\title{
The Meaning of the Common Market for the European Insurance Consumer
}

\author{
by G. W. de Wit*
}

At the creation of the common market in 1992 it is meaningful to ask what the consequences for the insurance industry will be.

This question can be approached from three points of view:

- Consequences for insurance economics

- Consequences for the insurance companies

- Consequences for the insurance consumers.

In the following we will briefly discuss the consequences for the insurance companies, while we will more in depth discuss the consequences for the insurance consumer.

When looking at the consequences for insurance companies the emphasis is in my opinion on a number of aspects like: uniformity of supervision (rigid or liberal, rules for the calculation of [long term] liabilities etc.) and uniformity and comparability in reporting etc. less emphasis will be on items like : do the companies have an interest in a common market, e. g. for their sales. The latter would in that case be closely connected with any consumer's interests.

When considering these items we should in my opinion differentiate between bulk lines and other ones. Bulk lines include all insurance, sickness insurance, medical benefits insurances purchased by individuals: life insurance, disability insurance, automobile insurance, fire insurance, liability insurance and a number of smaller insurances. The remainder includes the marine and commercial lines. In respect of the market this means that the bulk lines represent appr. $85 \%$ and appr. $15 \%$ are the other lines. (These are the figures for the Netherlands, for other countries they differ). Because the insurance market for the other lines (the "remainder") has already been internationalized to a considerable extent, we will in the following confine ourselves to the market for bulk lines.

The number of suppliers (the insurance companies) is high in some countries and smaller in others. The "insurers' density" considerably differs among the various countries. We would define insurers' density as the number of insurance companies per million inhabitants (a brief comment should be added to this: it is not entirely certain whether the number of insurance companies is counted in the same manner in all countries. E. g. are also the very small companies countcd? The number of insurance companies in Denmark for instance is improbably high in comparison with other countries).

\footnotetext{
* Professor of Erasmus University, Rotterdam (Holland).
} 
Apart therefrom we use the "insurance density". This is understood to mean total premium income (in US \$) per head of the population. Disadvantages of this concept are that also the non-bulk lines are included in premium income, that currency exchange ratios play a role and that the composition of the population is important.

We now find the following figures (for the year 1986): 1

\begin{tabular}{llrrr} 
Country & \multicolumn{3}{c}{$\begin{array}{c}\text { insurers' density } \\
\text { \# per mln. }\end{array}$} & $\begin{array}{c}\text { insurance density } \\
\text { premium \$ per caput }\end{array}$ \\
\hline Denmark & DK & 235 & 46 & 742 \\
The Netherlands & NL & 439 & 30 & 788 \\
Belgium & B & 302 & 30 & 570 \\
Ireland & IRL & 63 & 18 & 252 \\
Spain & E & 618 & 16 & 137 \\
Greece & GR & 154 & 15 & 46 \\
Britain & GB & 712 & 12.5 & 807 \\
France & F & 482 & 8.5 & 657 \\
Germany & D & 516 & 8.5 & 977 \\
Portugal & P & 47 & 4.5 & 76 \\
Italy & I & 207 & 3.5 & 252
\end{tabular}

The figures as such do not give much information, but combined with one another they provide an insight into the opportunities for insurers on the European market. We find the following graph :

Premium per caput in $\$$

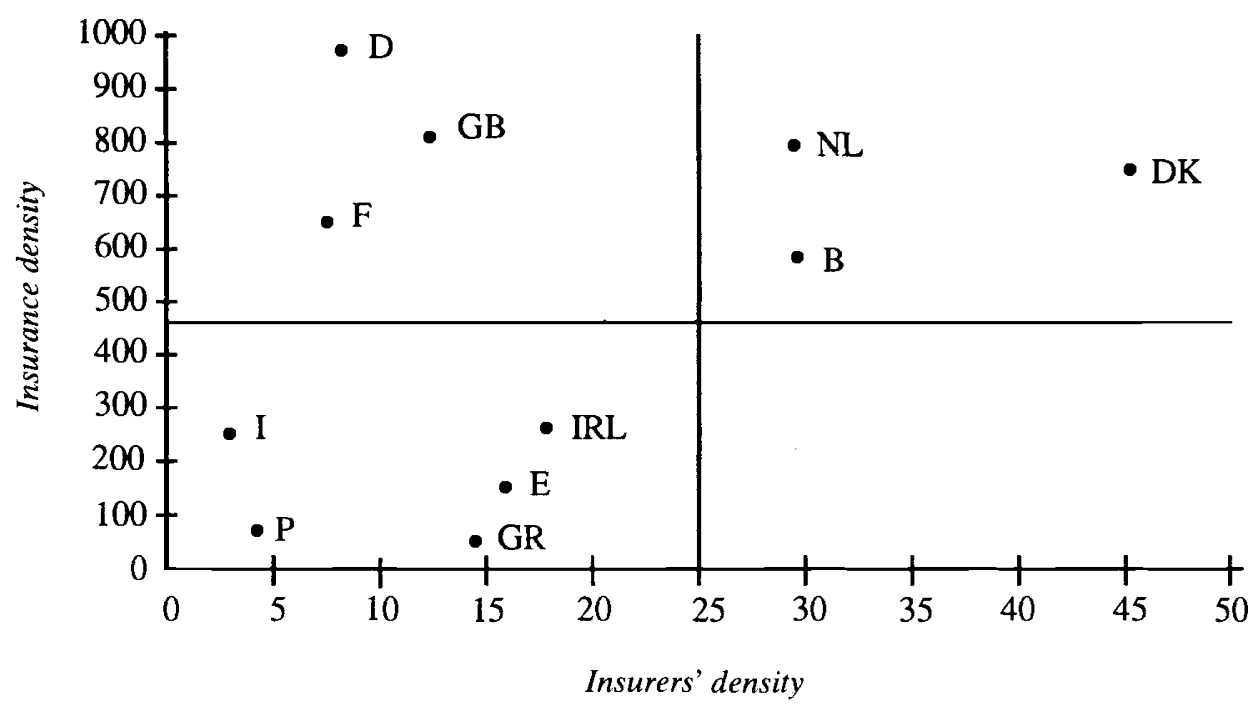

${ }^{1}$ Sigma, nr. 5, 1988. 
The graph can be divided into four sections:

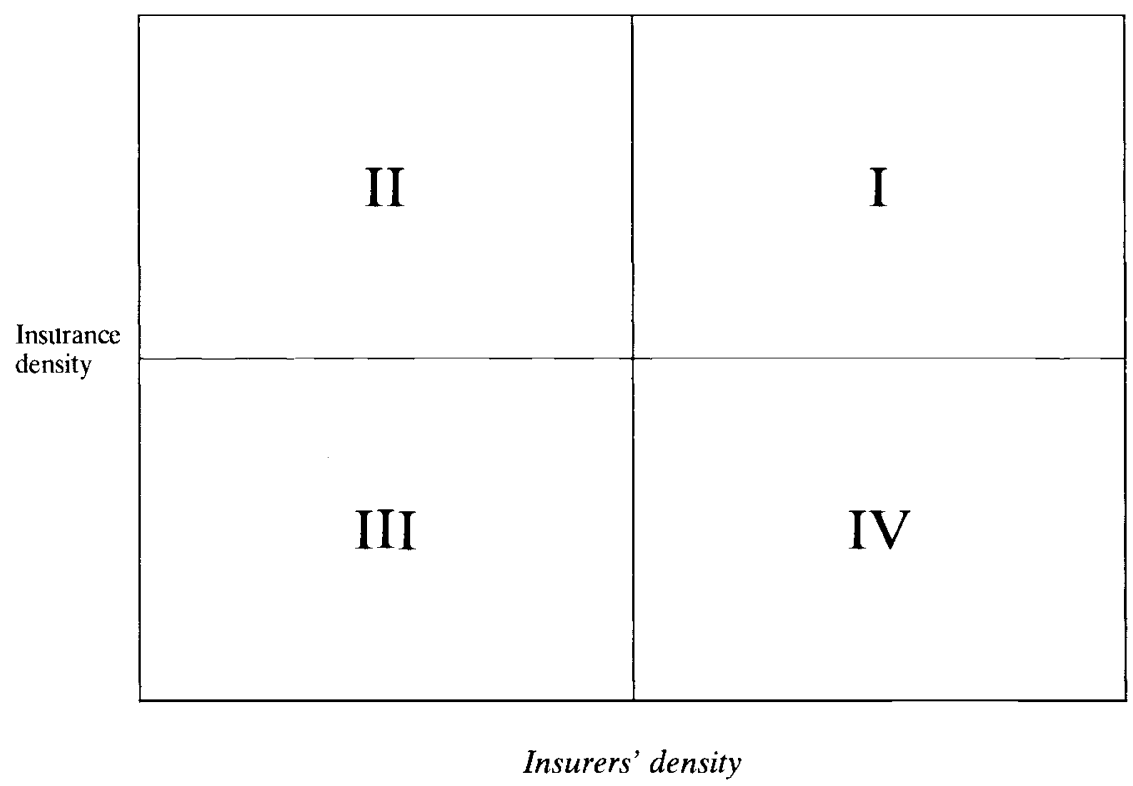

In Group I we see those countries where there is a high insurance density as well as a high insurers' density (we place a question mark in the case of Denmark). In these countries the market seems to reach a certain degree of saturation while the number of suppliers is high. Therefore a market for new entrants seems barely to exist there.

In group II we also see a high insurance density so that also here a strong expansion of the market seems hardly possible. The fact that the insurers' density is modest in this group might give rise to the idea that opportunities for new entrants exist. However, these appear barely existent.

Group III on the other hand does offer opportunities and this for two reasons: a low insurance density as well as a low insurers' density. Therefore one should not be surprised that many companies are turning to these countries because they see (great) marketing opportunities there. All roads are being followed: new establishments of their own, takeovers of existing local companies and certain types of joint ventures.

Finally Group IV does not include one single country. That stands to reason, because an extremely low insurance density can never be accompanied by a high density of insurers.

In spite of this picture one keeps seeing new types of joint ventures in Europe, including the creation of groups that cover several countries. In this manner a representation in a number of European countries from one focal point is achieved, which will, however, hardly affect the sale of bulk products. What may however happen (also if one establishes oneself directly in a different country) is that one is also going to sell the products which have a market share in a specific country but are hardly sold or are even unknown in another country, so as to gain a new market share in the latter country in that manner. 
If it would be probable that nothing much will change in the sales of insurers, what would the advantages of the common market to the insurance consumer be?

While it remains difficult for a company to simply establish itself in a different country, the situation is much easier for the consumer. ${ }^{2} \mathrm{He}$ has the opportunity to purchase insurance also in other countries (Euroshopping).

We should realize however, that bulk products are generally sold nearby: informational, local usage, claims settlement etc. In respect of these products there have to be urgent reasons to buy them far from home.

The Cecchini Committee made a number of calculations that should give an impression of the financial consequences for the citizens of the community if the frontiers are abolished in 1992. This committee arrives at extremely optimistic conclusions in its report. We will in the following have a look at these calculations and the conclusions drawn from them.

The rates for bulk products are showing great differences in respect of the different countries. ${ }^{3}$ What is the reason for this?

Roughly stated the rates consist of two components: a part that relates to the risk and a part that reflects the expenses. Bot components differ per country. It should be stated that the risk component reflects the main part of the total premium and that the expense part is the smaller. The Cecchini Committee ${ }^{4}$ has put together the premiums for a few lines in the different European countries. The committee confined itself to four lines (one of which does not really belong to the bulk lines):

- Life insurance: average expenses of a life insurance contract with a fixed initial term,

- Fire insurance: annual price of an insurance against fire and theft for a dwelling estimated at 70,000 ECU with household effects with a value of 28,000 ECU,

- automobile insurance: annual price of an all-risk policy, car 1.6 litres, driver having 10 years experience, with discount for no-claim,

- public liability insurance: annual premium for a machine factory with 20 employees and annual revenues of $1.29 \mathrm{mln}$. ECU

For these four types of insurance the following premiums were quoted:

\begin{tabular}{llll}
\multicolumn{2}{c}{ LIFE } & \multicolumn{2}{c}{ FIRE } \\
I & 392 & GB & 266 \\
B & 380 & I & 353 \\
E & 294 & F & 195 \\
F & 285 & NL & 164 \\
D & 225 & D & 144 \\
NL & 195 & E & 135 \\
GB & 150 & B & 118
\end{tabular}

\footnotetext{
2 "EC plans for open market for all insurance lines", Business Insurance, Dec. 4, 1989.

3 Term insurance in Europe, BEUC, nr. 51, 1988.

${ }^{4}$ All out for Europe, the Challenge 1992, Dutch summary of the report by Paolo Cecchini, 1988.
} 


\begin{tabular}{lr}
\multicolumn{2}{l}{ Automobile } \\
I & 942 \\
E & 758 \\
B & 494 \\
D & 436 \\
F & 413 \\
NL & 354 \\
GB & 316
\end{tabular}

Public liability

F $\quad 1,852$

I $\quad 1,508$

E $\quad 1,364$

D $\quad 1,257$

B $\quad 968$

GB $\quad 798$

NL $\quad 714$

In the form of a graph we get the following picture:

\section{Life insurance}

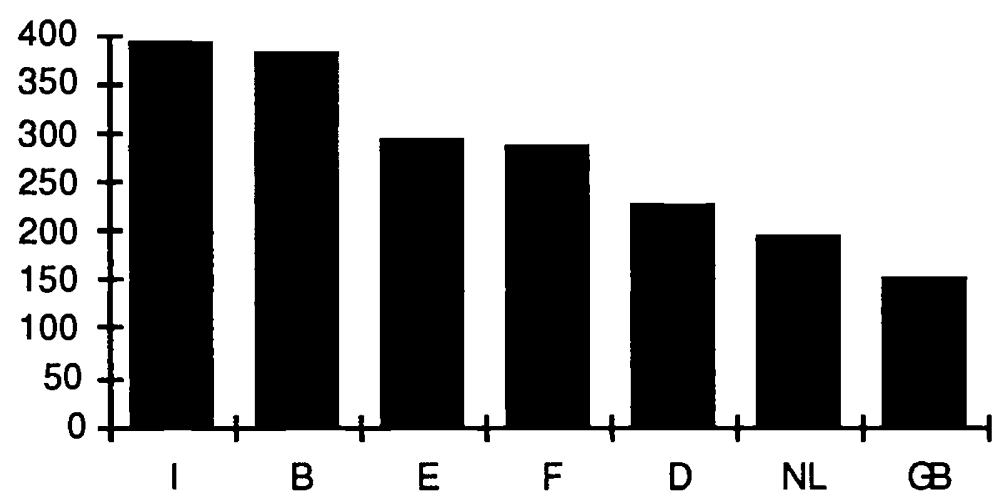

Fire insurance

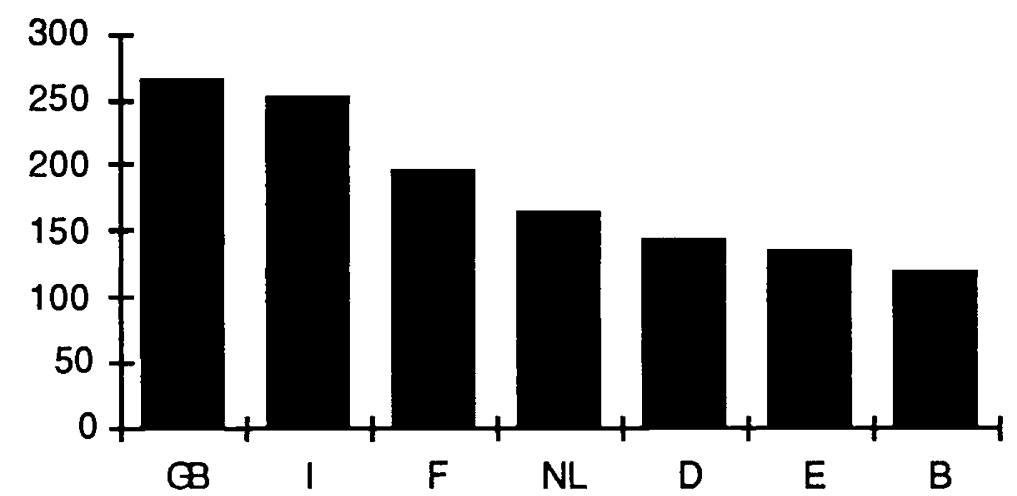




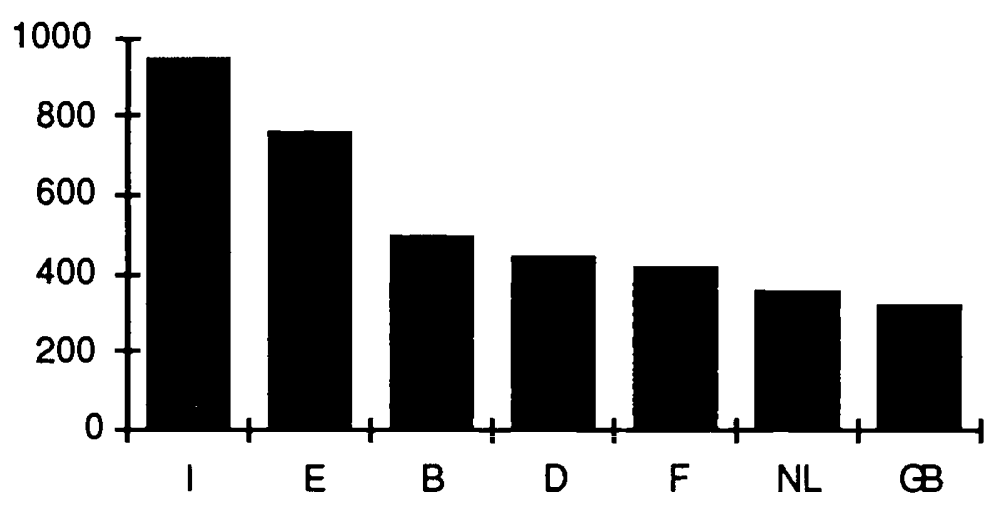

public liability insurance

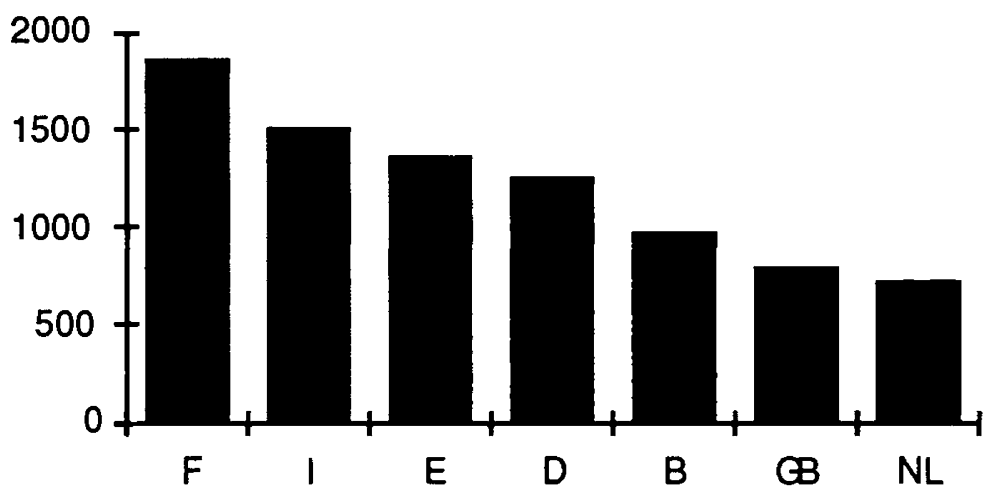

When evaluating these figures the Cecchini Committee did not take into account the sub-division by risk and expense component but simply assumed that especially the expenses were responsible for this. Maybe this conclusion was an obvious one: as a matter of fact it is apparent from the graphs that the countries with the most liberal supervision and consequently the strongest market forces (Great Britain and the Netherlands) also quoted the lowest premiums in three out of four cases. This conclusions may in itself be right: indeed free competition will result in lower rates; the more strict the supervision the higher the rates, but that does not explain the entire difference. That is why as of this moment the farther reaching conclusions of the committee are incorrect. Because what they did is that they 
took the average of the lowest four and subsequently assumed that the more expensive ones will grow towards the former. The differences in percentages of the four lines investigated in the various countries show the following picture as compared with the lowest four:

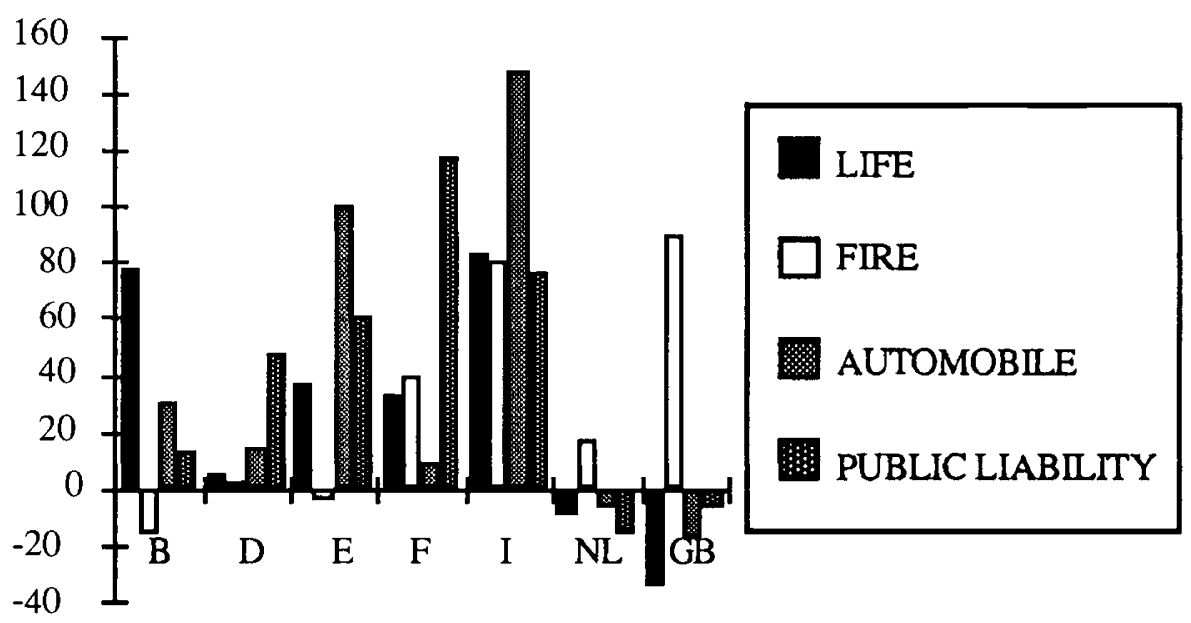

If the differences now disappear the committee calculated what the European consumer could save.

These savings are calculated to amount to 22 billion ECU for the entire financial sector (being the average of the high estimate of 33 billion ECU and the low estimate of 11 billion ECU). An analogous calculation for the insurance sector gives a low estimate of $800 \mathrm{mln}$. ECU and a high one of $2,200 \mathrm{mln}$. ECU, so that the committee arrives at expected savings for the insurance industry in the amount of 1.5 billion ECU.

This calculation is incorrect for two reasons:

- huge differences in risk premiums have not been taken into account

- it has been assumed Euroshopping will be fully realized, while it concerns in fact closeto-home products.

In the following we will discuss the risk component in the premium in somewhat more depth. If these differ substantially in the various countries and keep doing so, viz. if they are of a structural nature, there will never be a "uniform rate" in Europe. The question would then be: how do we mark these rates and if that would be so, Euroshopping would be much less meaningful.

Each country has its own mortality tables, sickness tables, but also its own experience in respect of car driving and fires. Apart therefrom the application of the different observations is not the same, in other words the rate structure is different everywhere (even in the event of equal observations). Besides there are substantial differences between the countries regarding liability legislation and there are separate tax rules everywhere. 
In the set-up of this paper it is not the intention to go into the legal and tax differences, so that we will confine ourselves in the following to the differences in the calculation factors and rate structures.

Extensive statistical observations are required to find the calculation factors. These do not exist in many countries while in some countries they are lacking entirely. On the basis of this fact it is very difficult in the first place to arrive at European comparisons. The data bases of the individual insurance companies often are not large enough to draw conclusions from these statistics. Yet big companies can have an advantage in this respect. Consequently this might turn out to be one of the advantages of the big European conglomerates.

Thanks to the technical position (processing and analysis) and the willingness to cooperate towards observations, an increasing number of such statistics will become available. Which means more information. In a free market - and that is what the European Community is aiming at - this will result in the premiums being tuned in with this information and hence with the risks. Because, if this would not be done, profits and losses will automatically follow. In this connection it is not material whether wrong premiums are used in a free market or whether these are compulsory (not tuned in with the risks). Only in the latter case it would be possible to smooth the differences by mutual settlement.

Let us first have a look at the differences in premium calculation factors. This is the most simple for life insurance. Only the mortality table is relevant in this connection and that is known for each country. The Groupe Consultatif des Associations d'Actuaires des Pays des Communautés Européennes has recently compared the various mortality tables. ${ }^{5}$ The results of this are shown below in two pictures: one for the ages 20 and 40 and one for the ages 60 and 80 .

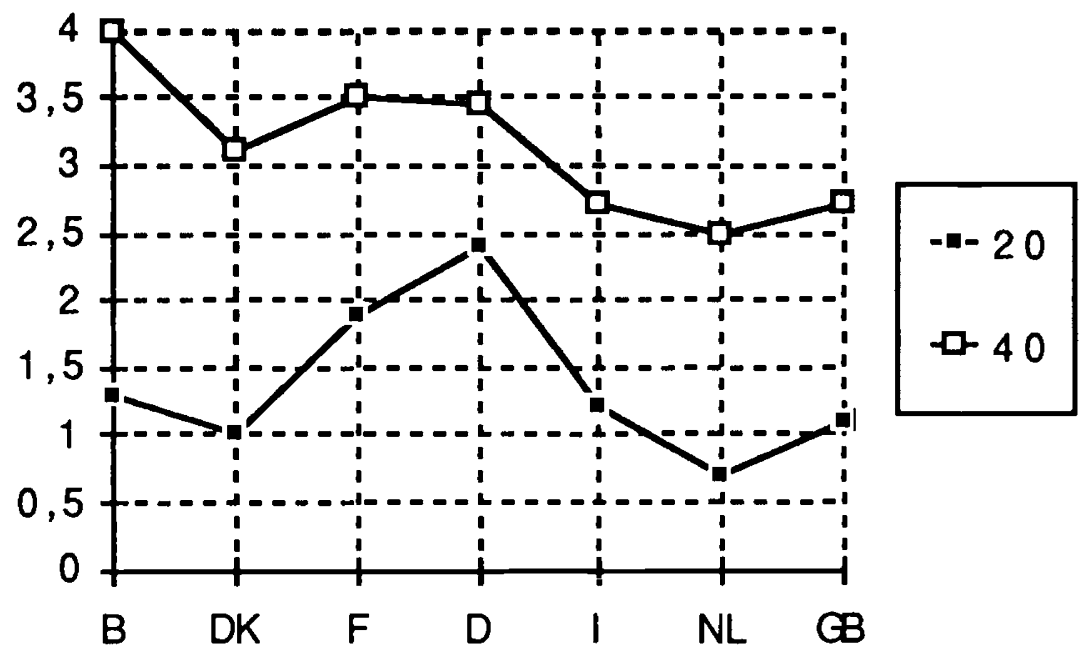

5 An actuarial study of mortality in the countries of the EC, J.J.McCutcheon (ed.), Groupe Consultatif des Associations d'Actuaires des Pays des Communautés Européennes. 


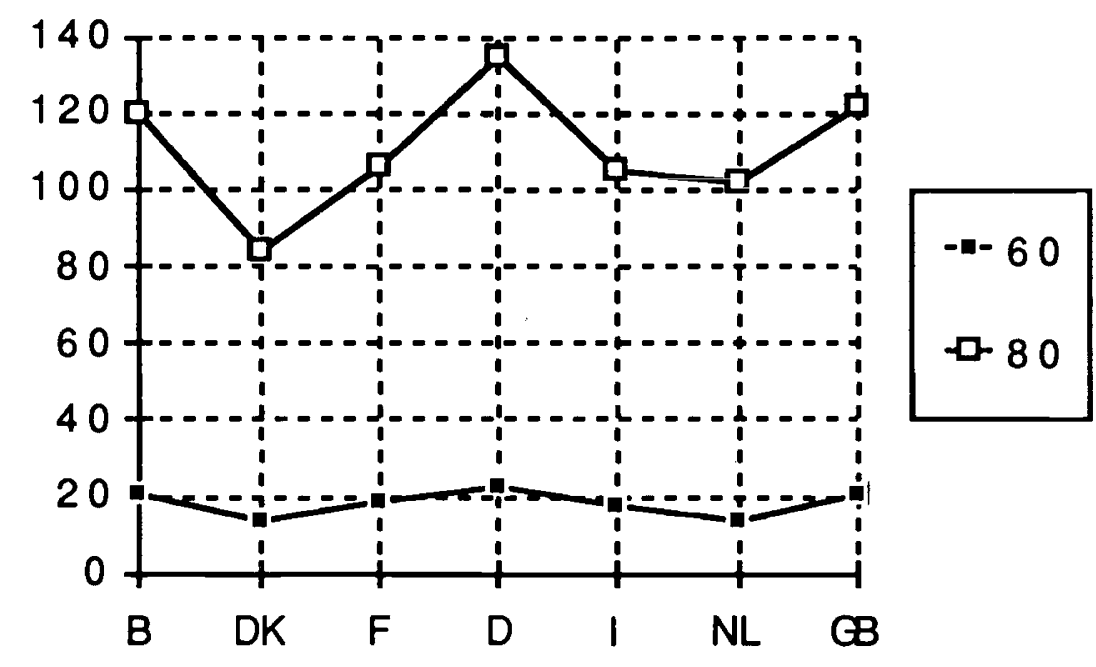

It becomes clear from these graphs that there are wide mortality variances in Europe. A disadvantage of the comparison is that the years of observation are so different for the various countries. Therefore we compare the most recent (1986) observations for Germany and the Netherlands and we find (per 1,000):

\begin{tabular}{lcr} 
Age & $\begin{array}{c}\text { the Netherlands } \\
1986\end{array}$ & $\begin{array}{c}\text { G.F. R. } \\
1986\end{array}$ \\
\hline 20 & 0.74 & 1.88 \\
40 & 1.61 & 3.18 \\
60 & 15.46 & 19.32 \\
80 & 103.06 & 124.58
\end{tabular}

This shows that also recently the differences remained substantial.

Here we find an interesting phenomenon, viz. the national frontiers. They are in fact irrelevant for the risk, but are working into the rates in this manner.

He who lives in Enschede is assessed by the mortality in the Netherlands, but he who lives in Gronau is supposed to be in line with German mortality. The distance between both towns is, however, no more than a few kilometres.

The national frontiers have been set long ago, sometimes as far back as the time of Charlemagne, but all of a sudden they appear to play a role in respect of rate setting. 
The meaning of the national frontiers seems not to fit in the new Europe any longer. In fact we should replace them by "risk frontiers". This does not apply to mortality only but to all lines of insurance. In real practice we have such risk frontiers in each country in regard of automobile insurance already (but in this case inside a country) the regionalisation of rates. This will now have to be applied throughout Europe.

Apart from languagc frontiers, monetary frontiers (differences in interest rates (of vital importance for life insurance) and tax frontiers also risk borders will have to be established.

That the development of mortality within an extensive territory is really always existent is also borne out by an example from the U.S. The following picture shows the average life expectation in different states in the Mid West: 6

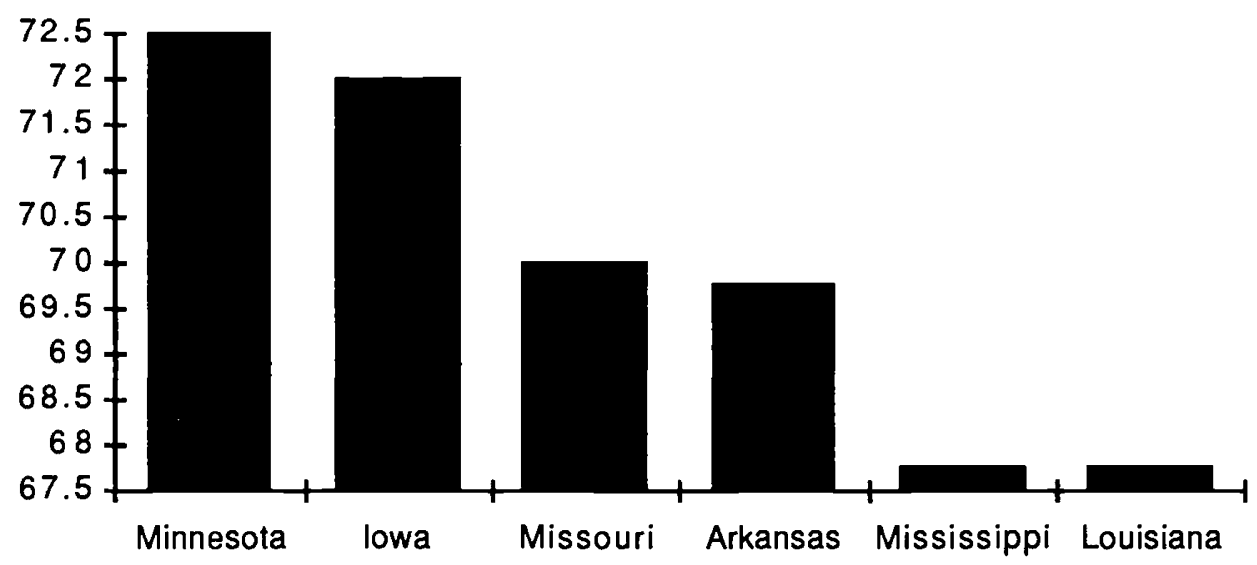

Apart from this example of life insurance that gave a picture of the wide variances in rate calculation factors, we would like to mention an example from automobile insurance because in this instance a difference in rate structure manifests itself apart from a difference in calculation factors.

A good analysis of the differences between the various automobile rates in Europe does not exist because not all countries have adequate statistic material at their disposal. Therefore we confine ourselves to the difference between Germany and the Netherlands. Two facts are playing a role: calculation differences and structural differences.

First a brief impression of the differences. We based ourselves on a Mercedes $300 \mathrm{E}$. We placed next to each other the initial premiums and the premiums after reaching the maximum no-claim discount. We found the following:

${ }^{6}$ Statistical Bulletin, Metropolitan Life, vol. 67, nr. 4, Oct.-Dec. 1986. 


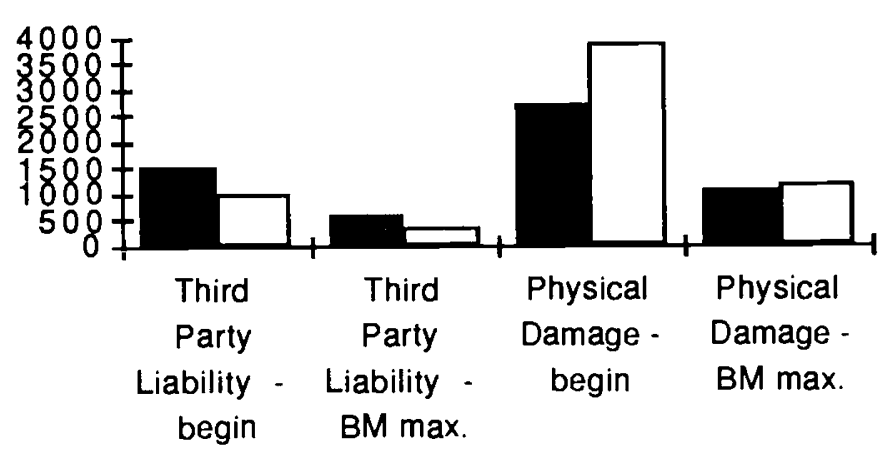

While the Third Party Liability insurance is cheaper in the Netherlands, the Third Party Liability + Physical Damage (All-Risk) cover is far and far higher. The reason is obvious: prices of spare parts in the Netherlands considerably exceed those in Germany. This also becomes manifest in the price of a new car of this type : in the Netherlands it is $35 \%$ higher than in Germany.

But it is not only the level that is different, also the structure varies. In Germany for instance the rate is based on the power of the motor (for Third Party Liability) and on the type (for Physical Damage) with an additional correction for the region and the bonus/ malus system (which ranges from 40 to 200 with a starting position of 175 (for Third Party Liability) and from 40 to 125 with a starting position of 125 (for Physical Damage). In the Netherlands on the other hand the weight of the car (for Third Party Liability) and its price (for Physical Damage) with a correction for the region, the age if the insured is under 24, and the number of kilometres to be driven if this is in excess 20,000 are the yardsticks. Apart from this there is of course also the bonus/malus system that ranges from 25 to 125 with a starting position of 100 .

Both systems have been derived from extensive statistical observations and are supported by good arguments. Yet there are substantial differences. The question arises whether or not harmonisation should be aimed at or whether these differences should remain in existence and if so, how the problems should be solved in the areas where the systems border.

It would be recommendable if actuaries would study the problems of both the calculating factors and the structure and analysed where the rating difference between the various countries originate from and to what extent these should and could be tuned in with one another.

There is another aspect. It appears to be extremely difficult to exactly realize how the differences in other areas (countries) are situated. It appears time and again that local know-how is indispensable. Big mistakes may result from lack of it.

But there is more. There is also a difference in thinking, in culture. We sometimes see for instance that within a society a specific idea about solidarity is being developed which 
one wants to see incorporated in ratings. A case in point is the Dutch medical insurance. As we are aware age plays an essential role in the rate setting for this line. Yet the Dutch society holds the opinion that age may play no, or anyway not an important role, younger people are supposed to be solidary with the older ones. If in one country solidarity elements play a role whereas this is not the case in other countries, this may simply result in big shifts if we want to adhere to the free market system. In such cases regulations will be required and these do not fit in with "sub markets" in a free European market. The way out is to characterize such an insurance as a social insurance for which category such rules would be possible (a closed market). Another example can be derived from the possibility or impossibility to obtain information. If in a certain country there is a ban on obtaining genetic information whereas this is not so in another country, this will also result in a certain movement in the total European market. This means that a flow of insurance will occur from markets that have this information at their disposal towards markets where this is not the case.

What will the result of all this be in the future free European market in which the consumer will be free to choose? We have already seen that we have to take into account:

- calculation factors

- structure and

- expenses.

This may be summarized in the following diagram:

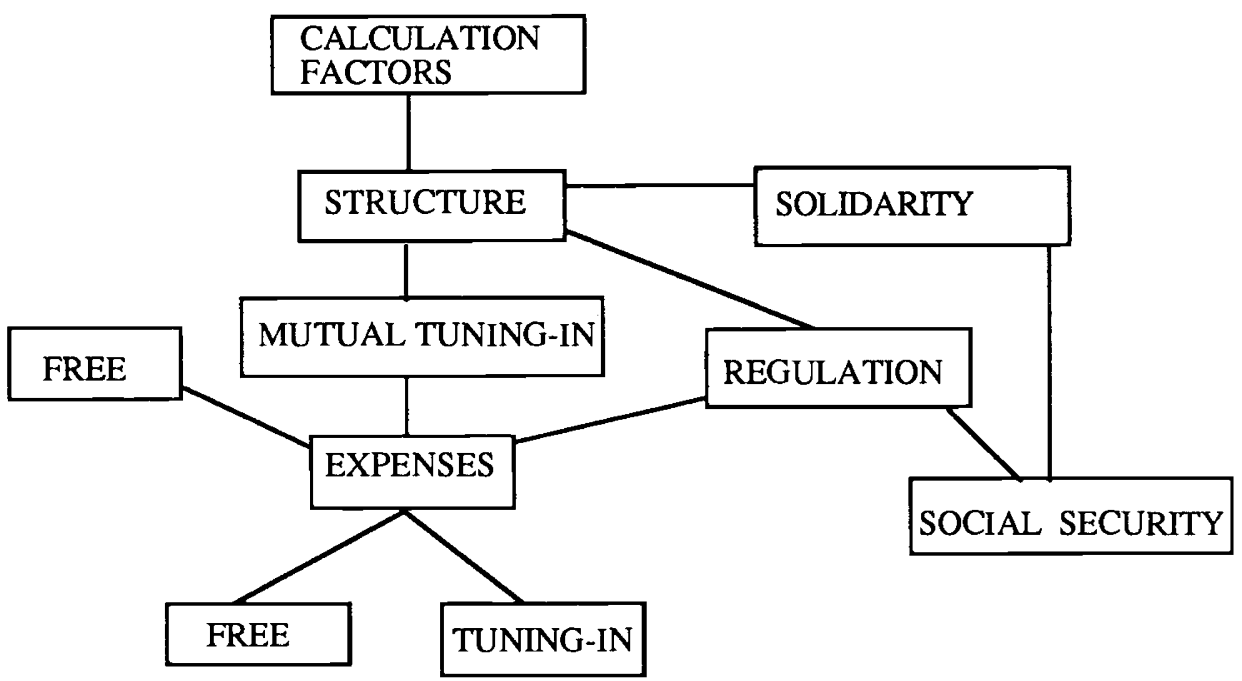

First we have to observe to what extent the calculation factors are basically different in various countries. Such differences should be accepted as facts. When the frontiers are free they will result in "risk frontiers" instead of the current national frontiers. 
Subsequently we will have to look at the calculation factors related to the structure. The more such structures, given the differences in calculation factors, have been tuned in with one another, the better. If we want to introduce solidarity elements into these structures which would remove us too far from real risk adjustment, this would in actual practice result in social security.

There are in principle three methods for the determination of the structure:

- leave the market planners entirely free. This may be the ideal of the European Community, but it does not seem very practical to get the closest possible mutual connection.

- a (soft) mutual tuning-in. This is not aimed at trust-like agreements but at the target: to achieve structures that are tuned in to one another as well as possible. It looks as if the European Community tends towards this form.

- fully regulate. This is the form that fits in with the current practice of the strict supervision in a number of countries. It would seem however, that maintaining this in a free European market would no longer be feasible. He who is nevertheless pursuing this, will arrive at a social security system like when solidarity elements are consciously built in.

Finally the expenses. In this respect full freedom seems easier to achieve than in the case of the structure. Naturally one should take care that no mix of calculation factors/structure and expenses occurs, which might result in hidden discount on net premiums. The expense loading included in the premium should have a connection with the actual expenses incurred. This may be subjected to free competition.

We now arrive at the following ideal diagram:

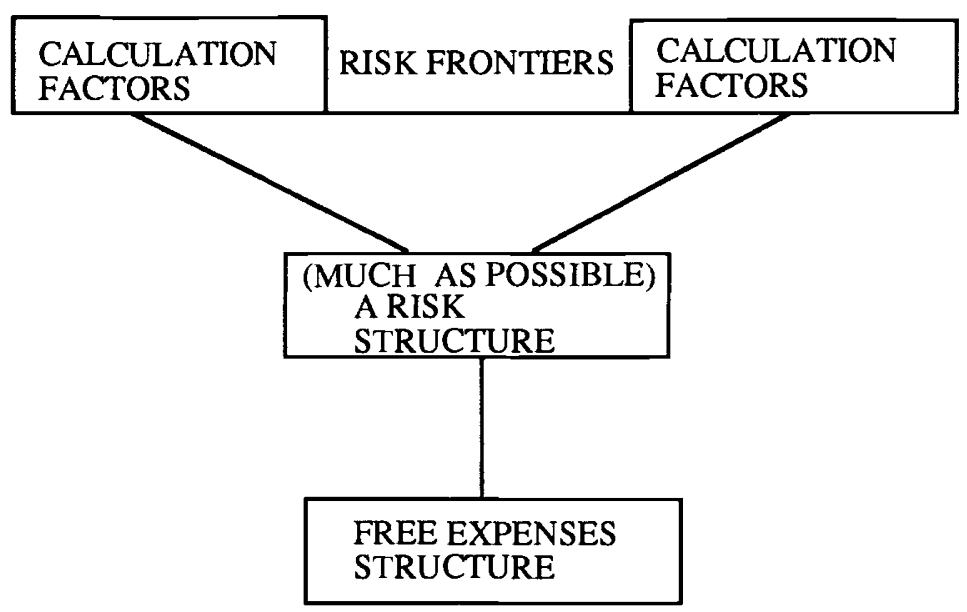

It will take a lot of time before such an ideal situation will have been realized and the European consumer will really take advantage of the common internal market. 